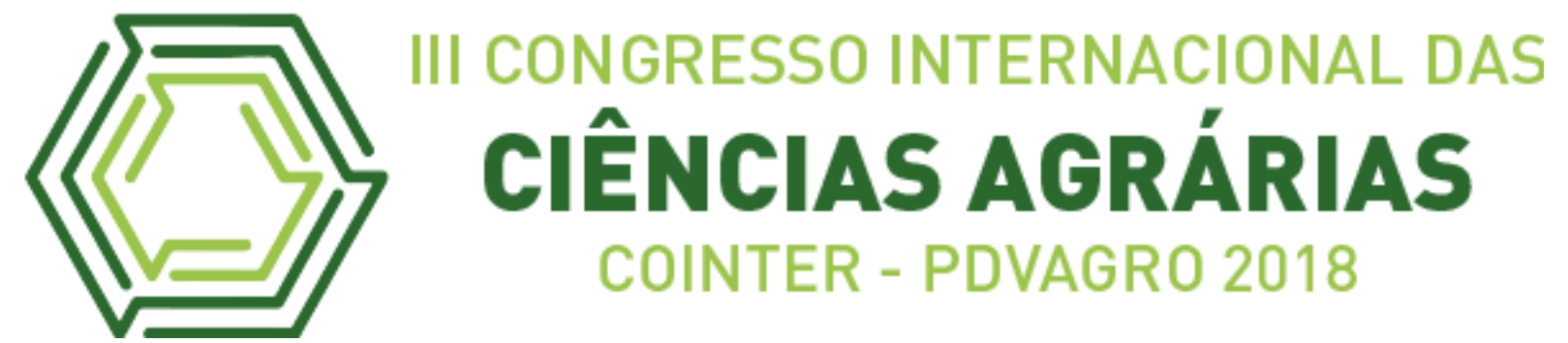

\title{
A IMPORTÂNCIA DA REALIZAÇÃO DE OFICINAS DE CACTOS ORNAMENTAIS PARA COMUNIDADES RURAIS.
}

\section{THE IMPORTANCE OF THE OFFICE OF ORNAMENTAL CACTUS OFFICES FOR RURAL COMMUNITIES.}

Apresentação: Relato de Experiência

Gislayne Kayne Gomes da Cruz ; Marilia Fernanda Santos ${ }^{2}$; Maria Alaine da Cunha

Lima $^{3}$; Andreza Ricaelly de Medeiros dos Santos ${ }^{4}$; Frederico Campos Pereira ${ }^{5}$

DOI: https://doi.org/10.31692/2526-7701.IIICOINTERPDVAGRO.2018.00699

\section{Introdução}

As plantas CAM (do inglês, Crassulacean Acid Metabolism), são plantas especialmente adaptadas às regiões áridas e semiáridas, com altas temperaturas diurnas, baixas temperaturas noturnas, alta radiação solar e baixo teor de água no solo. Essas plantas geralmente abrem seus estômatos durante à noite e os fecham durante o dia, dessa forma, minimizam à perda de água e apresentam por tanto, alta eficiência no uso da água. Dentre as famílias de angiospermas com metabolismo CAM citam-se Agaváceas, Bromeliáceas, Cactáceas, Crassuláceas, e Orquidáceas, muitas delas nativas da Caatinga (BARRETO, 2001).

Os cactos, em geral, apresentam diferentes finalidades, sendo a ornamentação, uma delas. O projeto Cactáceas Ornamentais surgiu inicialmente no ano de 2015 pelo o Coordenador do Núcleo Frederico Campos Pereira e professor do curso de Agroecologia, através de parcerias do NEA (Núcleo de Estudos em Agroecologia) entre o IFPB, Campus Picuí, e a comunidade Quilombola Serra do Abreu, com intuito de agregar valor ao trabalho da artesã Dona Maria, que trabalha atualmente com a produção de vasos e demais utensílios de barro. A Comunidade Serra do Abreu está inserida na região semiárida, que por sua vez, apresenta baixos índices de chuvas. Devido a isso, apresenta uma grande dificuldade na geração de renda, já que a maioria sobrevive da agricultura familiar, sendo a seca, um dos fatores que

\footnotetext{
${ }^{1}$ Curso Superior em Agroecologia, IFPB- Campus Picuí, gislayne.kayne@academico.ifpb.edu.br

${ }^{2}$ Curso Superior em Agroecologia, IFPB-Campus Picuí, mariliaagro505@gmail.com

${ }^{3}$ Curso Superior em Agroecologia, IFPB-Campus Picuí,alainelima1@gmail.com

${ }^{4}$ Curso Superior em Agroecologia, IFPB-Campus Picuí, ricaellya73@gmail.com

${ }^{5}$ Prof. CST em Agroecologia do IFPB Campus Picuí, fredcampus@yahoo.com.br
} 
mais contribui para o não sucesso na produção agrícola, já que as culturas plantadas são feijão e milho, espécies estas, não adaptadas ao clima local.

O Núcleo de Estudos em Agroecologia (NEA) vem buscando através de suas atividades agregar valor e contribuir no desenvolvimento da região, através de ações para que haja um novo olhar para o semiárido, com realização de eventos, palestras, dias de campos, minicursos e oficinas como forma de levar suporte para o produtor rural e comunidades.

Esse relato visa então, descrever a experiência vivenciada por agricultores familiares do Sítio Fortuna, município de Cuité-PB, após realização de oficinas educativas sobre práticas agroecológicas com uso de cactos ornamentais, bem como destacar a importância das mesmas para o desenvolvimento sustentável das comunidades locais. Pois o produtor familiar, quando recebe apoio suficiente, é capaz de produzir uma renda total, incluindo a de autoconsumo, superior ao custo de oportunidade do trabalho oferecido, uma vez que nas comunidades os suportes técnicos não acontece com frequência ou não possui esse acompanhamento por parte dos serviços técnicos do município que é a realidade da região Nordeste. No entanto são as universidades e institutos que acabam fazendo esse papel, fornecendo suporte ao produtor por meio de atividades, sendo assim é necessário e fundamental a formação de Núcleos de pesquisas que possam levar extensão rural para as comunidades, proporcionando mais conhecimento, práticas e despertando o trabalho em grupo.

\section{Relato de Experiência}

A importância de levar aos agricultores conhecimentos adquiridos em estudos realizados através dos Institutos Federais por meio de minicursos e oficinas é apenas uma das formas existentes de expandir conhecimento entre alunos e agricultores. O Núcleo de Estudos em Agroecologia fornece acessibilidade por meio dos projetos de Extensão, Pesquisa e Inovação cujos integrantes envolvidos, utilizam oficinas dinamizadas e inovadoras, além de permitir que os participantes interajam na prática sobre os assuntos expostos. Na (Figura 1) é apresentada a realização do curso FIC no assentamento Fortuna, que possibilitou uma troca de conhecimento entre as pessoas que se fazem presente na associação relatando sobre seus cultivos, criações, rendas e dificuldades para produzir durante a seca que a região Nordeste apresenta há alguns anos. Dessa forma, o conjunto de instrumentos que envolve a política pública, desde a reforma agrária até o crédito, a extensão rural e a educação do campo, são 
essenciais para garantir que os agricultores familiares ampliem suas potencialidades.

Figura 1: Curso FIC (Formação Inicial Continuada) realizado para agricultores no Assentamento Fortuna, município de Cuité. Fonte: Própria Autoria.

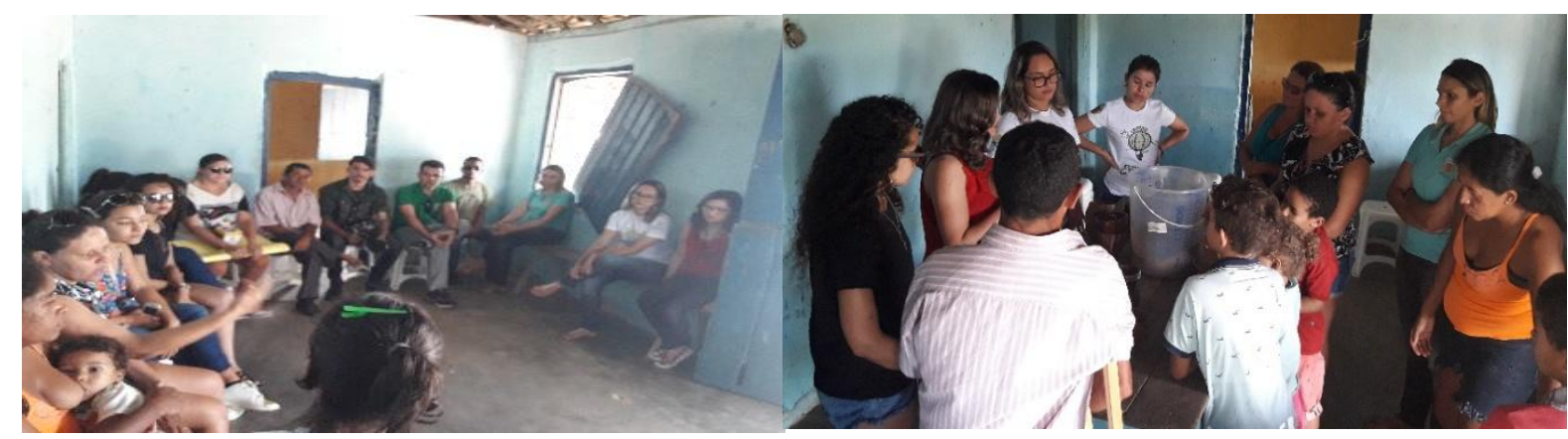

O projeto Cactáceas Ornamentais é um de tantos outros projetos realizados e vinculados ao Nea o qual desenvolveu-se dentro do próprio Núcleo, todos são interligados um ao outro como forma de continuidade, aproveitamento e sustentabilidade. O projeto Cactos ornamentais utilizam-se de elementos existentes em abundância na natureza assim destacando a utilização de substratos, principalmente, o rejeito de mica, que neste trabalho sai das montanhas de rejeito de minério lançadas a céu aberto e ganham utilidade fazendo misturas com areia lavada, esterco bovino e o composto oriundo do lixo verde (orgânico) e também faz parte dos projetos integrados no Núcleo possuindo parceria e apoio da Prefeitura do Município de Picuí.

Porquanto a relação da agricultura familiar com os recursos naturais é considerada positiva quando respeita a natureza, e apresentando controle sobre o processo de produtividade. Seu potencial para a valorização e sustentabilidade ecológica diz respeito à capacidade de conviver de maneira harmônica com ecossistemas naturais

Ademais, é por meio dessas oficinas, que procura-se despertar a criatividade das pessoas e apelo ao meio ambiente na construção de oficinas divididas na apresentação em duas partes com muita dinâmica ,os participantes podem interagir desde o preparo do substrato seguindo a proporção de $2 \times 1 \times 1 \times 1$, com uso de areia lavada, rejeito de mica e composto vegetal e esterco bovino( são todos misturados) no recipiente com auxílio de uma pá de jardinagem .Após o destaque dos cladódios presente na cactácea (Opuntia microdasys) a quais são plantas pertencentes à família Cactaceae e que são perenes e formam uma diversidade que se aproxima de 170 gêneros e 1500 espécies diferentes, distribuídas principalmente entre as Américas e melhores de ser utilizadas nas diversas maneiras tanto na alimentação animal e humana, ornamentação e inclusive com finalidades medicinais (PARDO, 
2002; FUERTES, 2005).

A próximo fase a ser realizada é a separação das raquetes e o plantio dentro de vasos de barros feito por uma louceira do Abreu, uma cultura que nos últimos tempos está ficando no esquecimento das pessoas pois as novas gerações falta interesse em aprender uma prática a qual eram repassada de geração para geração. Tendo como base, as oficinas que de tal modo procuram expandir o conhecimento adquirido entre o conhecimento cientifico ao tradicional aprimorando e incluindo como valor simbólico e significativo podendo fazer parte da renda familiar. No Entanto é através do trabalho manual da decoração que procura-se resgatar as práticas de artesanatos, pois é outro conhecimento que está ficando no esquecimento da cultura popular.

\section{Considerações}

Desse modo torna-se de grande importância expandir o conhecimento adquirido dentro dos Institutos Federais por meio de projetos Pesquisas, Extensões e Inovações tendo como base Núcleos de estudos em que levam aos agricultores de formas dinamizadas oficinas, palestras, dias de campos, e até mesmo curso de Formação Inicial Continuada. Fazendo a aproximação dos estudantes aos produtores rurais. Uma vez que os agricultores são quem produz os alimentos que estão presente na mesa de cada pessoa todos os dias, mas não recebem o devido suporte técnico o qual faz necessário para a orientação dos agricultores familiar, ter uma boa produtividade, conhecimento, e aumento da renda. Sendo assim os núcleos tem um papel muito importante orientando os agricultores e ensinando práticas inovadoras, usando materiais existente em abundância na natureza, assim como espécies de cactos ornamentais uma técnica a qual pode ajudar na renda e ser manuseada pela as mulheres como forma de artesanato.

\section{Referência}

BARRETO, A. F.: BARBOSA J. K. A. Mecanismo de resistência á seca que possibilitam a produção em condições do semiárido nordestino. Artigo publicado no $3^{\circ}$ Simpôsio Nordestino de Captação de água de Chuva. CCA/UFPB-PPG em Agronomia, Campina Grande-PB. 2001.

PARDO, O. Etnobotánica de algumas cactáceas y suculentas del Perú. Revista Chilena de Flora y Vegetación, 2002, año 5. http://www.chlorischile.cl. 